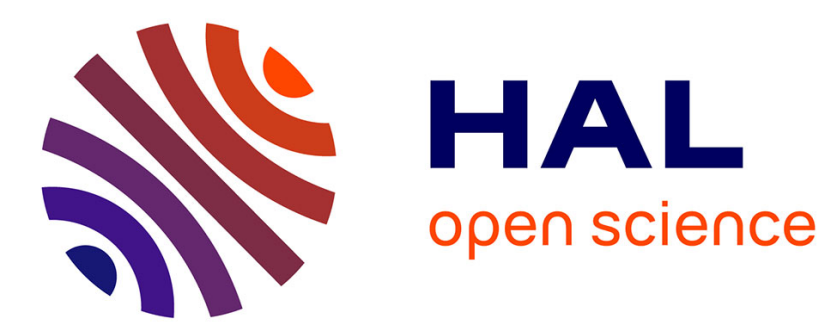

\title{
Low Pressure CVD of Tungsten Carbides
}

\author{
P. Tägtström, H. Högberg, U. Jansson, J.-O. Carlsson
}

\section{To cite this version:}

P. Tägtström, H. Högberg, U. Jansson, J.-O. Carlsson. Low Pressure CVD of Tungsten Carbides. Journal de Physique IV Proceedings, 1995, 05 (C5), pp.C5-967-C5-974. 10.1051/jphyscol:19955114 . jpa-00253784

\section{HAL Id: jpa-00253784 https://hal.science/jpa-00253784}

Submitted on 1 Jan 1995

HAL is a multi-disciplinary open access archive for the deposit and dissemination of scientific research documents, whether they are published or not. The documents may come from teaching and research institutions in France or abroad, or from public or private research centers.
L'archive ouverte pluridisciplinaire HAL, est destinée au dépôt et à la diffusion de documents scientifiques de niveau recherche, publiés ou non, émanant des établissements d'enseignement et de recherche français ou étrangers, des laboratoires publics ou privés. 


\title{
Low Pressure CVD of Tungsten Carbides
}

\author{
P. Tägtström, H. Högberg, U. Jansson and J.-O. Carlsson
}

Thin Film and Surface Chemistry Group, Department of Inorganic Chemistry, University of Uppsala, Box 531, 75121 Uppsala, Sweden

\begin{abstract}
Tungsten carbide films have been deposited by CVD from a $\mathrm{WF}_{6} / \mathrm{C}_{3} \mathrm{H}_{8} / \mathrm{H}_{2}$ gas mixture on several different substrate materials ( $\mathrm{Ta}, \mathrm{Si}, \mathrm{SiC}$ and $\mathrm{C}$ ). Single-phase WC films could easily be obtained on Ta substrates at $900^{\circ} \mathrm{C}$ using a total pressure of $100 \mathrm{mTorr}$ and a high linear gas flow velocity $(7 \mathrm{~m} / \mathrm{s})$. It was found that the low pressures favoured the growth of carbon-rich films and made the deposition zone for WC longer. The phase composition of the films and deposition rates were also strongly affected by the substrate material. The substrate dependence was attributed to the chemical reactivity of $\mathrm{WF}_{6}$.
\end{abstract}

\section{INTRODUCTION}

Tungsten carbide films have many mechanical, electrical and chemical properties which make them interesting as thin film materials. One of the most likely applications for tungsten carbide films is as wearresistant coatings, but they can also find use as e.g. high-temperature resistant materials and as active materials in heterogeneous catalysis. Both physical vapour deposition, PVD, and chemical vapour deposition, CVD have been used to grow tungsten carbide films (see e.g. ref. [1-8]). Hitherto, the most common tungsten sources in tungsten carbide CVD have been the halide compounds (i.e. $\mathrm{WCl}_{6}$ and $\mathrm{WF}_{6}$ ) while different hydrocarbons have usually been employed as carbon sources [4-8].

A problem in WC CVD is to deposit films consisting of only one phase and with uniform thickness. To the knowledge of the authors, tungsten-rich films containing several carbide phases have been obtained in most WC CVD studies[4-7]. An exception can be found in a paper by Takahashi and Itoh [8]. They were able to deposit single-phase WC films from a WCl $6 / \mathrm{C}_{3} \mathrm{H}_{8} / \mathrm{H}_{2}$ mixture at temperatures above $1200{ }^{\circ} \mathrm{C}$. However, this required a separation of $\mathrm{WCl}_{6}$ from the main gas flow until the gases were mixed in the vicinity of the substrate surface. This was explained by the high reactivity of $\mathrm{WCl}_{6}$ compared to $\mathrm{C}_{3} \mathrm{H}_{8}$ causing a preferential formation of metallic tungsten [8]. Mantle et al. deposited single-phase WC films provided that the substrates were pre-coated with $\mathrm{W}$ or $\mathrm{W}_{2} \mathrm{C}$ [4]. Thermodynamic calculations in the WCl $6 / \mathrm{CH}_{4} / \mathrm{H}_{2}$ system by Teyssandier and Ducarroir indicate that the difficulties to deposit single-phase WC films may be due to a narrow deposition window [9].

In this study it is proposed that the problems with the preferential formation of tungsten-rich phases as well as the difficulties to deposit single-phase WC films can partly be reduced by carrying out the deposition process at very low total pressures and with high linear gas flow velocities. This can be 
demonstrated e.g. by using $\mathrm{WF}_{6}, \mathrm{C}_{3} \mathrm{H}_{8}$ and $\mathrm{H}_{2}$ as precursors. $\mathrm{WF}_{6}$ is a highly reactive molecule compared to $\mathrm{C}_{3} \mathrm{H}_{8}$ and the halide will therefore react in the gas inlet region under the formation of metallic W and/or tungsten-rich phases such as $\mathrm{W}_{2} \mathrm{C}$. This leads to a subsequent depletion of the halide from the gas phase downstream in the reactor. One possibility to reduce this problem is to increase the reactivity of the hydrocarbon (e.g. use an aromatic compound) and/or to use a cold-wall CVD reactor. However, an alternative approach is to reduce the deposition pressure and increase the linear gas flow velocity of the reactants. This will increase the mean free path in the vapour and reduce the residence time of the molecules in the hot zone. Thus it is conceivable that the low pressure conditions significantly can reduce the reactions in the gas inlet region and increase the $\mathrm{WF}_{6}$ concentration downstream in the reactor, thereby favouring WC CVD in the deposition zone.

The aim of this study was to demonstrate that single phase WC films can be deposited at temperatures below $1000^{\circ} \mathrm{C}$ from a WF $6 / \mathrm{C}_{3} \mathrm{H}_{8} / \mathrm{H}_{2}$ mixture at very low pressures (and high linear gas flow velocities). The influence of the substrate material on the deposition process was also studied by thermodynamic calculations as well as experimental studies on four different substrates ( $\mathrm{Ta}, \mathrm{Si}, \mathrm{SiC}$ and $\mathrm{C}$ ).

\section{EXPERIMENTAL}

The deposition experiments were carried out in a hot-wall CVD system designed for film growth at very low total pressures (see Fig. 1).

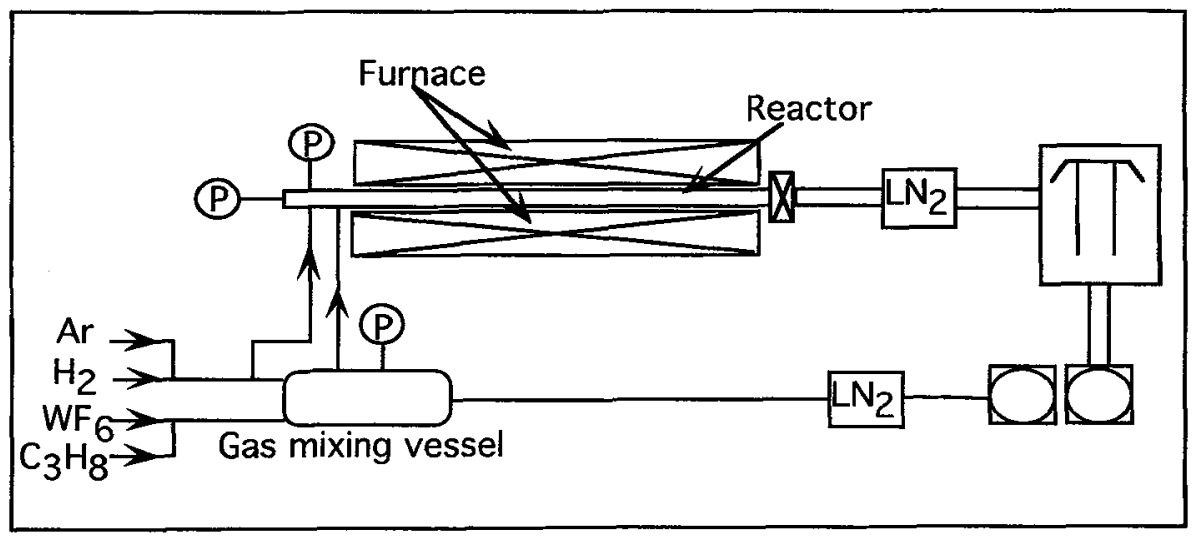

Figure 1: Schematics of the low-pressure CVD system

The system consists of an $80 \mathrm{~cm}$ long quartz reactor with an inner diameter of $25 \mathrm{~mm}$, pumped by a diffusion pump with a capacity of $2000 \mathrm{l} / \mathrm{s}$. In order to minimize back diffusion of oil, a liquid nitrogen trap is placed between the reactor and the pump. The gaseous reactants are supplied by a gas handling system, pumped with a standard roughing pump. From the gas handling system, the gases can be fed into the reactor, either through mass flow meters, or via a gas mixing vessel. Deposition pressures ranging from 100-500 mTorr can be obtained by throttling a gate valve. The base pressure of the system is in the $10^{-7}$ 
Torr range and leak rates of approximately $5 \cdot 10^{-8} \mathrm{Torr} \cdot 1 / \mathrm{s}$ can be achieved (this corresponds to a contamination level of $0.5 \mathrm{ppm}$ in a typical experiment). The temperature gradient throughout the reactor is less than $25^{\circ} \mathrm{C}$ at deposition temperatures of $900^{\circ} \mathrm{C}$.

The gaseous reactants $\mathrm{H}_{2}, \mathrm{C}_{3} \mathrm{H}_{8}$ and $\mathrm{WF}_{6}$ had a purity better than $99.9999 \%, 99.95 \%$ and $99.98 \%$, respectively. Prior to deposition, the internal walls of the gas mixing vessel were passivated by backfilling with $\mathrm{WF}_{6}$. The desired gas mixture was obtained by filling the vessel with one gas at a time and measuring the pressure with a capacitance manometer. Most experiments were performed with a $\mathrm{p}\left(\mathrm{C}_{3} \mathrm{H}_{8}\right) / \mathrm{p}\left(\mathrm{WF}_{6}\right)$ ratio of 19 and an $\mathrm{p}\left(\mathrm{H}_{2}\right) / \mathrm{p}\left(\mathrm{C}_{3} \mathrm{H}_{8}+\mathrm{WF}_{6}\right)$ ratio of 1 . To reduce oxidation of the samples during heating and cooling of the reactor, a small hydrogen flow at a pressure of 25 mTorr was applied. Upon charging the reactor with samples, an argon flow through the reactor was used to reduce contamination from air. In most experiments, the substrates were placed perpendicularly to the gas flow. However, in the pressure experiments (section 3.1), the substrates were placed in parallel to the flow.

The substrates used in this study were $\mathrm{Ta}, \mathrm{Si}, \alpha-\mathrm{SiC}$ and amorphous $\mathrm{C}$. The polycrystalline $\mathrm{Ta}$ substrates were cut from commercially available cold-rolled foils with a claimed purity of $99.9 \%$ while the $\mathrm{Si}$ and $\mathrm{SiC}$ substrates were cut from wafers of single-crystalline $\mathrm{Si}(100)$ (B-doped, resistivity 6.8-7.2 $\Omega \mathrm{cm})$ and $\alpha-S i C(0001)$, respectively. The $C$ substrates were prepared by depositing a thin continuous film of amorphous carbon on Si(100) by CVD. The details for the C CVD process have been presented elsewhere [10]. Prior to an experiment, the substrates were degreased and rinsed in methanol. The Si and $\mathrm{SiC}$ substrates were also etched in a 1:10 $\mathrm{HF}: \mathrm{H}_{2} \mathrm{O}$ solution to remove surface oxides.

The deposited WC films were characterised by X-ray diffraction (XRD), X-ray fluorescence spectroscopy (XRFS), X-ray photoelectron spectroscopy (XPS), Raman spectroscopy and atomic force microscopy (AFM). The amount of deposited $\mathrm{W}$-atoms per $\mathrm{cm}^{2}$ was measured by XRFS. Carbon and silicon have a negligible absorbance and the result from the XRFS analysis can therefore be converted into a film thickness, assuming that the film has an ideal density and uniform thickness. Phase identification with XRD was made with a Siemens D5000 powder diffractometer using CuK $\alpha$ radiation $(\lambda=1.5418 \AA)$ in a normal $\theta-2 \theta$ arrangement. The topography was studied with a Topometrix TMX 1200 AFM. Finally, the surface composition of the deposited films as well as of the substrates was analysed by XPS, using a PHI 5500 multitechnique instrument.

\section{RESULTS AND DISCUSSION}

\subsection{Influence of total pressure and linear gas flow velocity}

As discussed above, $\mathrm{WF}_{6}$ is a highly reactive molecule compared to most hydrocarbons. This difference may lead to a fast deposition of $\mathrm{W}$ (or $\mathrm{W}$-rich carbides) and a subsequent depletion of $\mathrm{WF}_{6}$ in the vapour when the reactants are transported through the CVD reactor. The depletion effect was investigated by depositing tungsten carbides at two different total pressures on a large number of Ta substrates, placed horizontally at equidistant positions in the reactor. It was found that the higher pressure (500 mTorr) and the lower gas flow velocity $(2.7 \mathrm{~m} / \mathrm{s})$ yielded a high deposition rate of $\mathrm{W}$-rich phases $\left(\beta-\mathrm{WC}_{1-\mathrm{x}}\right.$, metallic W...) at the entrance of the reactor (Fig.2). The film deposited at the gas inlet consisted mainly of metallic $\mathrm{W}$ while simultaneous deposition of $\mathrm{WC}$ and $\beta-W_{1-\mathrm{x}}$ was observed approximately $9 \mathrm{~cm}$ into the furnace. 
The $\beta-W C_{1-x}$ phase is a metastable carbide phase which is isostructural with TiC [11]. This phase is frequently obtained in PVD of tungsten carbide films (see e.g. ref. [1, 2]) but usually not in CVD. The deposition rate of the tungsten-containing films decreased strongly downstream in the reactor. No tungsten or tungsten containing deposit was observed at distances larger than $22 \mathrm{~cm}$ into the reactor.

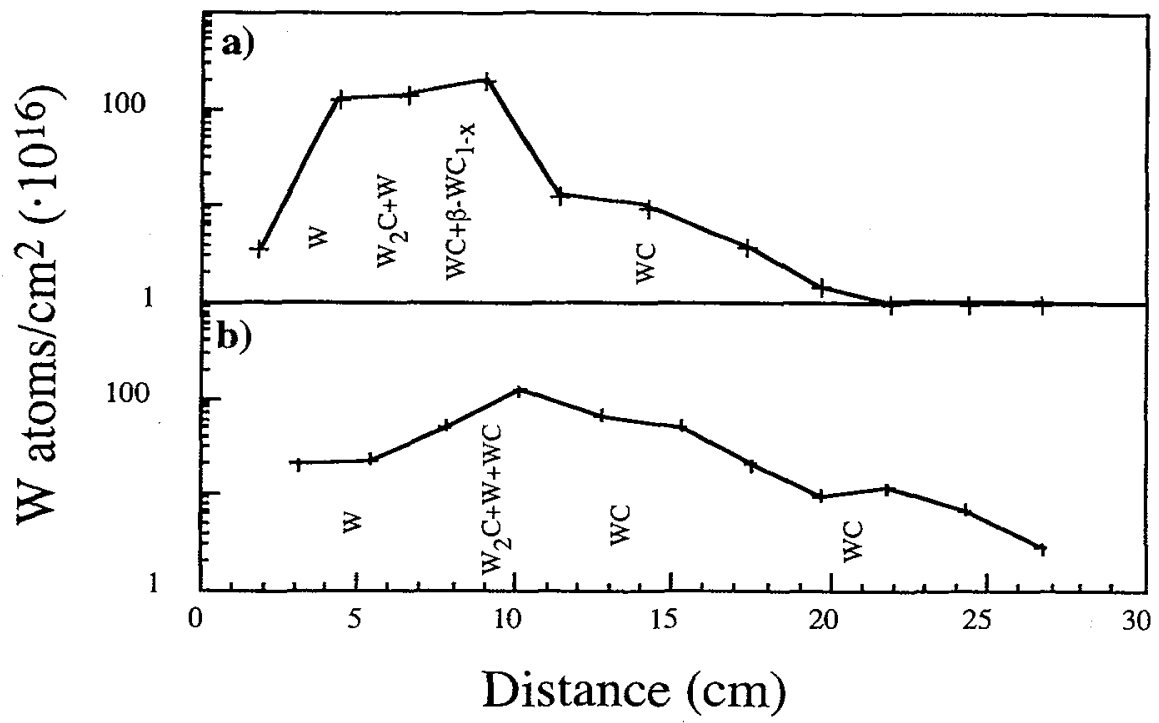

Figure 2: Thickness profile of tungsten carbide films on Ta at a total pressure of a) $500 \mathrm{mTorr}$ and b) $100 \mathrm{mTorr}$. Temperature in the centre of the reactor: $900{ }^{\circ} \mathrm{C}$. Deposition time: $30 \mathrm{~min}$. Vapour composition: $50 \% \mathrm{H}_{2}, 47.5 \% \mathrm{C}_{3} \mathrm{H}_{8}$ and $2.5 \% \mathrm{WF}_{6}$.

In contrast, the lower pressure (100 mTorr) and higher gas flow velocity $(7.4 \mathrm{~m} / \mathrm{s})$ resulted in a miuch more uniform deposition profile (Fig. 2). The deposition rate of the W-rich phases was reduced and no traces of the $\beta-W_{1-x}$ phase were observed. In addition, a rather broad zone for the deposition of singlephase WC was obtained in the centre of the reactor. The results show the importance of a low total pressure and a high linear gas flow velocity in CVD of $\mathrm{WC}$ from $\mathrm{C}_{3} \mathrm{H}_{8} / \mathrm{WF}_{6} / \mathrm{H}_{2}$.

\section{2 Influence of substrate material on WC CVD}

A series of preliminary low-pressure CVD experiments showed that the WC CVD process was strongly influenced by the substrate material. This effect was studied in a series of deposition experiments as well as by thermodynamic calculations for four different substrate materials ( $\mathrm{Ta}, \mathrm{C}, \mathrm{SiC}$ and $\mathrm{Si}$ ) which may be of interest for future applications. The thermodynamic calculations were carried out by using a free-energy minimization technique [12].

The thermodynamic calculations show that the Si substrate is highly reactive towards $\mathrm{WF}_{6}$ at the high temperatures used in the deposition process (see Table I). This is in agreement with the behaviour observed in W CVD on Si substrates (see e.g. ref. [13]). 
Table I. Summary of thermodynamic calculations and experimental results (deposition conditions: see Fig. 2).

\begin{tabular}{|c|c|c|c|c|c|}
\cline { 2 - 6 } \multicolumn{1}{c|}{} & \multicolumn{2}{c|}{ Thermodynamic calculations } & \multicolumn{2}{c|}{ Experimental results } \\
\hline Substrate & $\begin{array}{c}\text { Gaseous } \\
\text { products }\end{array}$ & $\begin{array}{c}\text { Solid } \\
\text { products }\end{array}$ & $\begin{array}{c}\text { Driving force } \\
-\Delta \mathrm{G}(\mathrm{kJ} / \text { mole })\end{array}$ & $\begin{array}{c}\text { Film } \\
\text { composition }\end{array}$ & $\begin{array}{c}\text { Film thickness } \\
\left(\mathrm{W} \text { atoms } / \mathrm{cm}^{2}\right)\end{array}$ \\
\hline $\mathrm{Si}$ & $\mathrm{SiF}_{3}, \mathrm{SiF}_{2}, \mathrm{SiF}_{4}$ & $\mathrm{WSi}_{2}, \mathrm{SiC}$ & 350.7 & $\begin{array}{c}\mathrm{WSi}_{2}, \mathrm{~W}_{2} \mathrm{C}, \\
\mathrm{WC}, \beta-\mathrm{WC}_{1-\mathrm{x}}\end{array}$ & $2.51 \cdot 10^{18}$ \\
\hline $\mathrm{SiC}$ & $\begin{array}{c}\mathrm{SiF}_{3}, \mathrm{SiF}_{2}, \\
\mathrm{SiF}_{4}, \mathrm{HF}\end{array}$ & $\mathrm{C}, \mathrm{WC}$ & 255.2 & $\mathrm{WC}, \beta-\mathrm{WC}_{1-\mathrm{x}}$ & $4.30 \cdot 10^{17}$ \\
\hline $\mathrm{C}$ & $\mathrm{HF}$ & $\mathrm{WC}$ & 251.8 & none & 0 \\
\hline $\mathrm{Ta}$ & $\mathrm{HF}, \mathrm{TaF}_{5}, \mathrm{H}$ & $\mathrm{Ta}$ C, WC & 533.0 & $\mathrm{WC}$ & $6.14 \cdot 10^{17}$ \\
\hline
\end{tabular}

The calculations suggest that $\mathrm{Si}$ should react with the reaction gas mixture under the formation of volatile silicon fluorides and solid $\mathrm{WSi}_{2}$ and $\mathrm{SiC}$. This reaction is substrate-driven with a rather high driving force $(-\Delta \mathrm{G}=350.7 \mathrm{~kJ} / \mathrm{mole})$. The predicted reactivity of $\mathrm{Si}$ was confirmed in deposition experiments where severe substrate etching and deposition of a mixture of $\mathrm{WSi}_{2}, \mathrm{~W}_{2} \mathrm{C}, \mathrm{WC}$ and $\mathrm{WC}_{1-\mathrm{x}}$ were obtained. The deposition rate was relatively high (approximately $4 \cdot 10^{16} \mathrm{~W}$ atoms $/ \mathrm{cm}^{2} \cdot \mathrm{min}$ ). Moreover, the films exhibited a poor morphology and a poor adhesion. Consequently, Si must be considered as a highly unsuitable substrate material for the experimental conditions used in this study.

In contrast, thermodynamics suggest that carbon (graphite) should be completely inert towards the reaction gas mixture (see Table I). This means that only WC (or other tungsten carbide phases) should be deposited and that no substrate etching should occur. The experiments, however, showed that no tungstencontaining films could be deposited on amorphous carbon substrates. Furthermore, XPS analyses of the carbon substrates showed no signal from any tungsten-containing species on the surface. This suggests that some reaction step(s) in the CVD of tungsten carbides on carbon is strongly suppressed or inhibited. For this reason, we have carried out preliminary experiments in a UHV system to study the adsorption and surface reactions of $\mathrm{WF}_{6}$ on different carbon substrates (for a description of the UHV system, see ref. [14]). The experiments show that the sticking coefficient for $\mathrm{WF}_{6}$ adsorption on graphite and amorphous carbon is very low [15]. Hence, it is conceivable that the difficulties to deposit WC on amorphous carbon is due to a low adsorption rate of $\mathrm{WF}_{6}$ on this substrate material. It is likely that carbide deposition could be obtained at higher deposition pressures where more reactive subhalides can easily be formed by homogeneous reactions in the vapour.

The thermodynamic calculations also show that $\mathrm{SiC}$ should be reactive towards the reaction gas mixture (see Table I). WF 6 can react with $\mathrm{SiC}$ under the formation of volatile silicon fluorides, solid WC and solid $C$. However, the driving force $(-\Delta G)$ for this process is only slightly higher than for the homogeneous reaction (cf. the $\mathrm{C}$ and $\mathrm{SiC}$ substrates in Table I) indicating that $\mathrm{SiC}$ should be rather inert towards $\mathrm{WF}_{6}$. The experimental results also confirmed that $\mathrm{WC}$ can be deposited on $\mathrm{SiC}$ together with small amounts of the cubic $\beta-W_{1-x}$ phase (see Fig. 3). The deposition rate on $\mathrm{SiC}$ was fairly low (approximately $7 \cdot 10^{15} \mathrm{~W}$ 
atoms $\left./ \mathrm{cm}^{2} \cdot \mathrm{min}\right)$. Furthermore, the films were smooth and exhibited good adhesion to the substrate material (see Fig. 4).

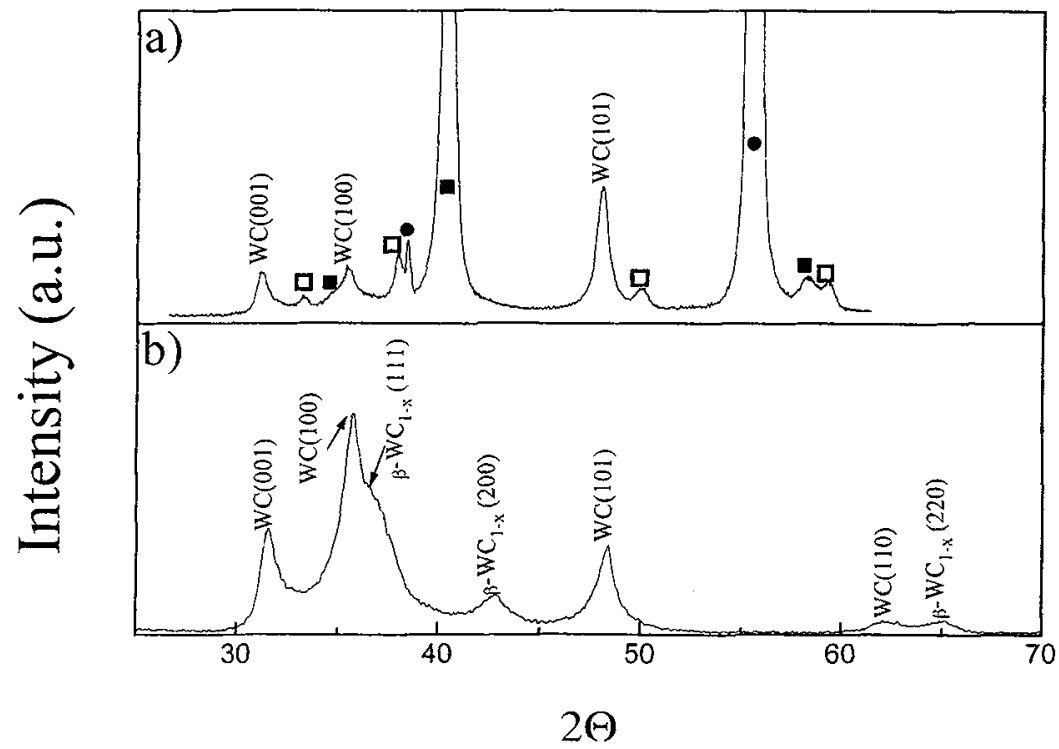

Figure 3. X-ray diffractograms of a) a single-phase WC film deposited on $\mathrm{Ta}$ and $\mathrm{b}$ ) $\mathrm{WC} / \mathrm{WC}$-x film deposited on $\mathrm{SiC}$ at $900^{\circ} \mathrm{C}$. Deposition pressure: $100 \mathrm{mTorr} . \square \mathrm{Ta} 2 \mathrm{C}, \mathbf{\square} \mathrm{TaC}, \bigcirc \mathrm{Ta}$.

Finally, the best film quality in this study was obtained with Ta as substrate material. However, the thermodynamic calculations show that $\mathrm{Ta}$ is also a highly reactive substrate. The most important substrate reaction is a reduction of $\mathrm{WF}_{6}$ by $\mathrm{Ta}$ according to the reaction:

$5 \mathrm{WF}_{6}(\mathrm{~g})+6 \mathrm{Ta}(\mathrm{s}) \rightarrow 5 \mathrm{~W}(\mathrm{~s})+6 \mathrm{TaF}_{5}(\mathrm{~g})$

This reaction has recently been confirmed in UHV adsorption experiments by Högberg et al. [16]. Furthermore, Ta exhibits a strong affinity to carbon and easily forms $\mathrm{TaC}$ and/or $\mathrm{Ta}_{2} \mathrm{C}$ in the presence of carbon-containing gases.

The experimental results showed that WC films could easily be deposited on Ta in a broad temperature and vapour composition range. At $900{ }^{\circ} \mathrm{C}$, single-phase WC films were deposited with $\mathrm{p}\left(\mathrm{C}_{3} \mathrm{H}_{8}\right) / \mathrm{p}\left(\mathrm{WF}_{6}\right)$ ratios ranging from 10 to 39 . Metallic $W$ and/or $W_{2} \mathrm{C}$ could be obtained with $\mathrm{p}\left(\mathrm{C}_{3} \mathrm{H}_{8}\right) / \mathrm{p}\left(\mathrm{WF}_{6}\right)$ ratios below 10 . No free carbon could be detected in the films by Raman spectroscopy or XRD. Moreover, the diffractograms confirmed that $\mathrm{TaC}$ and $\mathrm{Ta}_{2} \mathrm{C}$ are formed during the deposition process. The film thicknesses were typically $2.5 \cdot 10^{17}-1.0 \cdot 10^{18} \mathrm{~W}$ atoms $/ \mathrm{cm}^{2}$ after a deposition time of 60 minutes. This corresponds to a film thickness of about 500-2000 Å assuming ideal film density. Finally, it was found that the WC films deposited on Ta exhibited a smooth nodular morphology and a good adhesion (see Fig. 4). 

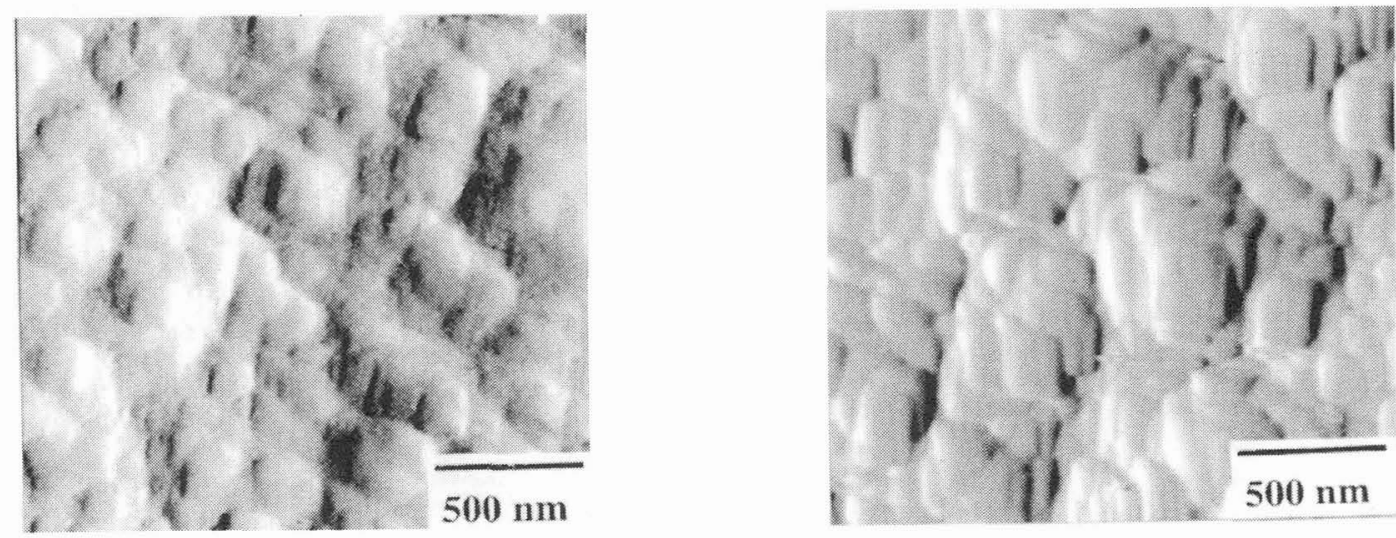

Figure 4. AFM micrographs of $\mathrm{WC}_{\mathrm{WC}} \mathrm{C}_{1-\mathrm{x}}$ film deposited on SiC (left) and a single-phase WC film deposited on Ta at $900^{\circ} \mathrm{C}$ (right). Deposition pressure: $100 \mathrm{mT}$ Torr.

\section{CONCLUDING REMARKS}

Thin films of single-phase WC have been deposited in a hot-wall CVD reactor using very low pressures (100 mTorr) and high gas flow velocities. It was demonstrated that lower total pressures and higher gas flow velocities reduced the $\mathrm{WF}_{6}$ depletion in the vapour, increased the carbon content in the films and increased the length of the WC deposition zone. Single phase WC films could easily be obtained on Ta substrates. The deposition rates of the WC films obtained in this study were rather low $(\max .0 .2 \mu \mathrm{m} / \mathrm{h})$. However, no attempts have been made to optimize the deposition process with respect to deposition rate. It is likely that considerably higher deposition rates can be obtained by a careful tuning of the process.

The deposition rate and phase composition of the carbide films were strongly affected by the substrate material. The high deposition rate on Si was explained by the chemical reactivity of this substrate towards $\mathrm{WF}_{6}$. This also resulted in a mixture of different phases including $\mathrm{WSi}_{2}$. The fact that single phase WC films were obtained on $\mathrm{Ta}$, while a phase mixture of $\mathrm{WC}$ and $\mathrm{WC}_{1-\mathrm{x}}$ was deposited on $\mathrm{SiC}$ suggests that the $\mathrm{WC}_{1-\mathrm{x}}$ phase is stabilized by Si. Moreover, no deposition was observed on clean carbon substrates. This was probably due to a low adsorption rate of $\mathrm{WF}_{6}$ on carbon surfaces.

The results in this study clearly demonstrate that well-characterized WC films can be deposited on certain substrate materials. However, lower deposition temperatures and higher deposition rates are desirable for the deposition of e.g. wear-resistant coatings. It is likely that this can be accomplished with more reactive carbon precursors. Further investigations with unsaturated and aromatic carbon precursors will therefore be carried out in our laboratory.

\section{Acknowledgments}

The authors are most grateful to Lars Norin for his skilful assistance with the AFM study. This work was supported by the Swedish Natural Science Research Council (NFR) and the Swedish Research Council for Engineering Studies (TFR). 


\section{References}

[1] Cavaleiro A. and Vieira M.T., Thin Solid Films 197 (1991) 237-255.

[2] Fuchs K., Rödhammer P., Bertel E., Netzer P. and Gornik E., Thin Solid Films 151 (1987) 383395.

[3] Trinidade B., Vieira M.T. and Bauer-Grosse E., Thin Solid Films 252 (1994) 82-88.

[4] Mantle H., Gass. H. and Hintermann H. E., "CVD of Tungsten Carbide (WC)", 5th Int. Conf. CVD, Buckinghamshire, England, J. M. Blocher, H. E. Hintermann and L. H. Hall Eds. (The Electrochem. Soc. Princeton, 1975) pp. 540-555.

[5] Archer N. J., "Tungsten Carbide Coatings on Steel", 5th Int. Conf. CVD, Buckinghamshire, England, J. M. Blocher, H. E. Hintermann and L. H. Hall Eds. (The Electrochem. Soc. Princeton, 1975) pp. 556573 .

[6] Kelly C. M., Garg. D. and Dyer P. N., Thin Solid Films 219 (1992) 103-108.

[7] Garg D. and Dyer P. N., Tungsten Carbide Erosion Resistant Coating for Aerospace Components", CVD of refractory metals and ceramics vol. 168, MRS Symp., Boston 1989, T. M. Besmann and B. G. Gallois Eds. (MRS, Pittsburgh 1990) pp. 213-220.

[8] Takahashi T. and Itoh H., J. Cryst. Growth 12 (1972) 265-271.

[9] Teyssandier F., Ducarroir and Bernard C., "Investigation of the Deposition Conditions for pure WC", 7th Int. Conf. CVD, Los Angeles 1979, T. O. Sedgwick and H. Lydtin Eds. (The Electrochem. Soc., Princeton 1979) pp. 398-411.

[10] Johansson A. S. and Carlsson J. O., accepted for publication in Thin Solid Films.

[11] Von Krainer E. and Robitsch J., Planseeberichte für Pulvermet., 15 (1967) 46-56.

[12] Noläng B., Thesis, Acta Univ. Upsal., 691 (1983).

[13] Creighton J. R. and Parmeter J. E., Crit. Rev. Solid State and Mater. Sci. 18 (1993) 175-238.

[14] Jansson U., Appl. Surf. Sci. 73 (1993) 51-57.

[15] Tägtström P. and Jansson U., unpublished results.

[16] Högberg H., Tägtström P. and Jansson U., to be published. 